\title{
IMPLEMENTATION OF OPERANT CONDITIONING THEORY FOR HABITUATION OF STUDENTS IN WORSHIP AT SMPIT RABBI RADHIYYA CURUP
}

\section{IMPLEMENTASI TEORI OPERANT CONDITIONING UNTUK MEMBIASAKAN SISWA DALAM BERIBADAH DI SMPIT RABBI RADHIYYA CURUP}

\author{
Sutarto ${ }^{1}$ \\ ${ }^{1}$ Institut Agama Islam Negeri, Curup \\ sutarto@iaincurup.ac.id
}

\begin{abstract}
Recently, many Islamic schools have special programs to bias students in voting, but they do not yet have the right formula for implementing the plan. This study examines the implementation of operational conditioning to form students in theory at the Rabbi Radhiyya Curup Islamic Junior High School (SMPIT). This study used a qualitative approach, with data sources for the principal, Ustaz and ustazah, and students. Data collection using unstructured interviews. The validity of the data obtained was checked using triangulation of sources, then analyzed using the Miles and Huberman model. The results showed that several types of worship that were accustomed to students were congregational prayer, rawatib circumcision prayer, duha prayer, tahajud prayer, tahsin, tahfiz, and circumcision fasting Monday Thursday and fasting circumcision on Arafah day. The pattern of refraction is carried out in three stages, knowing, feeling, and doing. Operant conditioning theory applied to familiarize
\end{abstract}

Keywords: theory operant conditioning, habituation, worship

\begin{abstract}
ABSTRAK
Akhir-akhir ini banyak muncul sekolah bercirikhas ke-Islaman yang memiliki program khusus untuk membiaskan siswa dalam beribadah, namun belum memiliki formula yang tepat dalam mengimplementasikan program tersebut. Penelitian ini berujuan untuk mengkaji secara mendalam tentang implementasi teori operant conditioning untuk membentuk kebiasaan siswa dalam beribadah di Sekolah Menengah Pertama Islam Terpadu (SMPIT) Rabbi Radhiyya Curup. Penelitian ini menggunakan pendekatan kualitatif, dengan sumber data Kepala Sekolah, ustaz dan ustazah serta siswa. Pengumpulan data menggunakan wawancara tidak terstruktur. Data yang diperoleh dicek keabsahannya dengan menggunakan triangulasi sumber, kemudian dianalisis dengan menggunakan model Miles dan Huberman. Hasil penelitian menunjukkan bahwa beberapa jenis ibadah yang dibiasakan kepada siswa adalah shalat berjamaah, shalat sunat rawatib, shalat duha, shalat tahajud, tahsin, tahfiz dan puasa sunat Senin Kamis serta puasa sunat hari arofah. Pola pembiasannya dilakukan melalui tiga tahap, knowing, feeling dan doing. Teori operant conditioning yang diterapkan untuk membiasakan siswa adalah memberikan reword dan punishmant, selain itu memberi contoh dan melakukan kegaiatan mentoring.
\end{abstract}

Katakunci : teori operant conditioning. pembiasaan, ibadah 


\section{A. PENDAHULUAN}

Sekolah bercirikhas ke-Islaman memiliki peran yang sangat penting dalam membentuk kebiasaan siswa beribadah. Untuk mewujudkan hal tersebut, sekolah membuat berbagai program khusus, seperti sholat duha, tahsin dan tahfiz, solat berjamaan, MABIT dan sebagainya. Perogram khusus tersebut ada yang diimplementasikan melalui sistem full day school (Raharjo et al., 2018), boarding school (Wuryandani et al., 2016), kegiatan ekastra kulikuler keagamaan (Hambali \& Yulianti, 2018; Kholisotin \& Minarsih, 2018) dan sebagainya. Namun berbagai program khusus yang diimplementasikan tersebut ada yang belum memiliki formula yang tepat untuk membiasakan siswa dalam beribadah.

Studi tentang pembiasan siswa dalam beribadah sudah banyak dilakukan oleh peneliti terdahulu (Faozan et al., 2019; Harahap et al., 2019; Is, 2018; Keikazeria \& Ngare, 2020; Rusady et al., 2017; Yasyakur, 2017). Riset terdahulu kebanyakan hanya mendiskripsikan upaya yang dilakukan oleh guru dalam membisakan siswa untuk melakukan ibadah pada aspek-aspek tertentu, seperti sholat duha, solah berjamaah dan menjalin kerjasama dengan orang tua. Begitu juga terkait dengan teori operant conitioning, riset terdahulu kebanyakan mengkaji teori ini dalam tataran konsep (Muazzaroh, 2017), dan diimplementasikan dalam pembentukan karakter (Alfiah, 2018; Muktar, 2019; Ulya, 2020). Sejauh ini belum ditemukan penelitian khusus yang mengkaji tentang implementasi teori operant conditioning dalam membiasakan siswa beribadah.

Penelitian ini akan mengkaji bagaiman implementasi teori operant conditioning untuk membentuk kebiasaan siswa dalam beribadah di Sekolah Menengah Pertama Islam Terpadu (SMPIT) Rabbi Radhiyya Curup. Kajian ini difokuskan pada dua aspek. Pertama, jenis-jenis ibadah yang dibisakan kepada siswa dan pola bembiasaan yang digunakan. Implementasi reinforcement dan punishmant dalam teori operant conditioning untuk membiasakan siswa beribadah.

Kajian ini penting untuk dilakukan, mengingat SMPIT Rabbi Radhiyya Curup merupakan sekolah umum bercirikhas keIslaman yang sangat diminati oleh masyarakat khususnya di Curup Kaupaten Rejang Lebong. Salah satu yang menjadi daya tarik masyarakat adalah karena sekolah tersebut memiliki program khusus dalam membiasakan anak untuk menjalankan ibadah. Dengan adanya kajian ini, diharapkan dapat mengungkanpkan secara jelas bagaimana implementasian teori 
operant conditioning dalam membiasakan siswa beribadah.

\section{B. TINJAUAN PUSTAKA}

\section{Konsep Dasar Teori Operant Conditioning}

Teori operan conditioning merupakan salah satu teori pembelajaran yang berafiliasi pada pendekatan behavioral. Pendekatan behavioral merupakan pendekatan pembelajaran yang menyatakan bahwa perilaku harus dinyatakan dalam bentuk pengalaman yang dapat diamati, bukan dalam bentuk proses mental (Asfar et al., 2019; Nahar, 2016). Bengitu juga halnya dengan teori operan conditioning yang menekankan bahwa pembentukan tingkah laku dapat dilakukan melalui pengkondisian dengan meggunakan instrument (Kausar \& Suyadi, 2020). Instrumen digunakan untuk memberikan berbagai kosekuensi dari perikaku individu agar mengulangi atau meninggalkan perilaku tersebut (Rianita et al., 2018).

Teori operant conitioning dikembangkan oleh B.F Skinner yang didasarkan hasil penelitian yang dikemukakan oleh E.L Thorndike. E.L Thorndike pada tahun 1906 melakukan pengamatan pada seekor kucin yang diletakkan di dalam kotak dan meletakkan makanan di luar kotak (Santrock, 2017). Untuk bisa ke luar dari kotak, kucing harus dapat membuka palang dalam kotak tersebut. Pada awalanya kucing memberikan respon secara tidak efektif, namun akhirnya secara tidak sengaja kucing menginjak palang, pintu terbuka dan bisa ke luar. Pada saat dikembalikan ke dalam kotak lagi, kucing melakukan kegiatan acak, akhirnya terinjak palang, pintu terbuka dan bisa ke luar. Pada percobaan bertikutnya ternyata kucig tidak lagi melaukan tindakan acak, melainkan langsung menginjak palang, pintu terbuka lalu ke luar (Santrock, 2017). Dari hasil pengamatan tersebut Thorndike menyimpulkan bahwa perilaku dapat dibentuk melalui Law of Effect atau hukum efek. Perilaku walaupun pada awalnya dilakukan secara tidak sengaja, namun menghasilkan sesuatu yang positif maka akan dilakukan secara berulang-ulang dan akan menjadi kebiasaan, sedangkan perilaku yang diiring dengan hasil negatif akan mengalami perlemahan (Purwanto, 2018).

Konsep utama dari pemikiran dan penelitian yang dilakukan oleh Thorndike adalah berkisar pada Stimulus dan Respon (S-R). Respon yang dilakukan secara benar tehadap sitimulus akan menguat dan mengalahkan respon yang salah terhadap stimulus, sedangkan respon yang tidak tepat semakin lama semakin melemah (Purwanto, 2018). Dasar teori inilah yang 
dikembangkan oleh Skinner kemudian melahirkan teoi operant conditioning.

Teori operant conditioning digagas oleg Skinner pada tahun 1938 (Santrock, 2017). Pembentukan perilaku dapat dilakukan dengan pengkondisian menggunakan instrumen. Instrumen digunakan untuk memberikan konsekuensi dari perilaku yang ditampilkan oleh individu (Santrock, 2017). Konsekuensi yang diberikan ada yang menyenangkan dan ada yang tidak menyenangkan (Umar, 2018). Jika perilakukan yang ditampilkan sesuai dengan yang diharapkan, maka individu akan diberi konsekuensi yang menyenangkan berupa penguatan atau imbalan atau reinforcement (Makki, 2018), namun apabila perilaku yang ditampilkan tidak sesuai dengan yang diharapkan maka individu akan diberi konsekuensi yang tidak menyenagkan berupa punishmant atau hukman (Makki, 2018). Pemberian imbalan atau hukuman, menurut teori operant conditionig bersifat sementara dan bukan sasaran akhir yang akan dicapai oleh individu (Zamzami, 2018). Sasaran akhir yang akan dicapai dari pemberian reward adalah pemberian penguatan dan memotivasi individu agar melakukannya secara berulang-ulang sehingga menjadi terbiasa. Sedangkan sasaran akhir dari pemberian punishmant adalah untuk mengghilangkan respon yang tidak tepat terhadap stimulus (Afandi, 2017).

\section{Reinforcement}

Reinfoecement atau penguatan adalah rangsangan yang diberikan kepada seseorang dengan tujuan untuk memperkuat munculnya perilaku yang baik (Ratnawati, 2016). Reinforcement dapat diartikan sebagai konsekuensi menyenangkan yang diberikan kepada individu sebagai akibat dari respon yang tepat terhadap stimulus yang yang diberikan (Aini et al., 2019). Reinforcement memiliki peran yang sangat penting dalam pembelajaran. Dengan adanya reinforcement, individu dapat mengetahui bahwa apa yang dilakukan sudah benar dan sesuai dengan yang diharapkan atau belum (Ramadhan, 2020). Reinforcement juga dapat memberikan motivasi kepada individu untuk melakukan hal-hal yang sama atau melakukan hal-hal yang lebih baik dikemudian hari (Ramadhan, 2020), juga bisa menjadikan setiap individu untuk melakukan kegiantankegiatan yang dapat setia dan loyal terhadap, memberikan mereka untuk mempraktikkan perilaku yang baik (Saihu, 2019: 72).

Secara garis besar reinforcement dapat dikelompokkan menjadi dua, yaitu reinforcement positif dan reinforcement negatif (Hindayati \& Mayasari, 2019). Reinforcement positif adalah reinforcement 
yang diberikan guna memperkuat respon atau tingkah laku tertentu agar tetap dipertahankan atau ditingkatkan, dilakukan dengan cara memberikan stimulus yang menyenangkan (Solina et al., 2020). Reinforcement positif dapat berupa reward baik dalam bentuk verbal atau kata-kata dan kalimat (seperti baik, bagus, lanjutkan san sebagainya), maupun non verbal seperti angukan, senyum, sentuhan, gestur tubuh, acungan kempol, tepuk tangan, sertifikat penghargaan bahkan bisa berbetuk materi atau benda (Febianti, 2018). Reinforcement negartif yaitu reinforcement yang diberikan untuk memperkuat respon atau tingkah laku dengan mengurangi atau menghilangkan sitimulus yang tidak menyenangkan (Solina et al., 2020). Reinforcement negatif dapat secara verbal atau kata-kata dan kalimat (sepeti kurang benar, sebaiknya begini dan sebagainya), maupun non verbal seperti geleng kepala, gestur tubuh yang menunjukkan tidak suka dan sebagainya .

\section{Punishmant}

Secara bahasa kata punishmant berasal dari bahasa Latin, berasal dari kata punire berarti memberikan hukuman seseorang akibat melakukan kesalahan pelanggaran (Yusuf, 2018). Dalam bahasa Inggris, punishmant memiliki makna yang sama dengan kata law, berarti hukuman atau siksaan (Ma'arif, 2017).
Punishmant atau hukuman merupakan konsekuensi yang diberikan kepada individu guna untuk menurunkan atau mengilangkan respon atau tingkah laku tertentu (Ma'arif, 2017). Punishman diberikan apabila individu tidak mau merespon stimulus yang diberikan (Ma`arif, 2018).

Punishmant dibagi menjadi dua, yaitu Presentation punishment dan removal punishment. Presentation punishment adalah hukuman yang diberikan kepada individu dengan cara memberikan stimulus yang tidak menyenangkan, seperti memberikan tugas tambahan jika individu tidak mengerjakan tugas tertentu (Sujiantari et al., 2016). Removal punishment yaitu hukuman yang diberikan dengan cara mengilangkan atau menunda sesuatu yang diinginkan (Yusuf, 2018), seperti tidak dizinkan melanjutkan materi seelanjutnya jika belum menguasai materi yang diberikan.

\section{Pembiasaan dalam Presfektif Pedidikan Islam}

Secara gramatikal, kata pembiasaan berasal dari kata "biasa" mendapat awalam "pe" dan akhiran "an". Biasa berarti seperti sedia kala atau sesuatu yang tidak bisa dipisahkan dari kehidupan sehari-hari (Tim Penyusun Kamus Pusat Bahasa, 2016). Pembiasaan bermakna suatu proses yang dilakukan sehingga sesuatu menjadi terbiasa dilakukan (Cahyaningrum et al., 2017) . 
Dalam presfektif pendidikan Islam, pembiasaan merupakan salah satu metode yang dapat digunakan dalam proses pembelajaran. Metode pembiasaan dapat guna untuk membiasakan peserta didik agar perfikir, berbicara, bersikap dan berperilaku sesuai dengan ajaran Islam (Rahim \& Setiawan, 2019). Pendapat lain menjelaskan, metode pembelajaran merupan suatu cara yang dapat digunakan untuk menciptakan kebiasaan atau tingkah laku yang baik bagi peserta didik (Firmansyah, 2018).

Pembiasaan dapat dilakukan dengan cara dengan mengucapkan atau melakukan sesuatu secara berulang-ulang (Angdreani et.al., 2020). Pembiasaan juga dapat dilakukan dengan menciptakan situasi atau lingkungan tertentu, sehingga individu mendengarkan, menyaksikan, mengalami dan mengikuti secara terus menerus (Hidayatullah, 2019).

Pembiasaan dalam lingkungan sekolah dapat dilakukan dengan dua cara. Pertama, pembiasaan terprogram, yaitu pembiasaan yang dilakukan melalui kegiatan tertentu secara terencana dan terjadwal dalam kurun waktu tertentu. Kedua, pembiasaan tidak terprogram, yaitu pembiasaan yang dilakukan secara tidak terencana tetapi dapat berimplikasi dalam membiasakan seseorang, seperti melakukan tindakan spontan secara berulang-ulang, memberi keteladanan, dan melakukan kegiatan rutinitas secara teratur (Angdreani et al., 2020).

Dalam kontek psikologi, banyak teori yang dapat digunakan untuk membiasakan seseorang. Pendekatan behavioristik menawarkan beberapa teori, diantaranya adalah teori connnectionism, teori klasikal conditiong, teori operant conditioning, teori sistematic behavior, teori cosial learning dan sebagainya (Rufaedah, 2018).

Al-Qur'an secara implist menjelaskan bahwa pembiasaan harus dilakukan secara bertahap dan dapat digunakan untuk perubah perilaku negatif menjadi perikalu positif (Nata, 2016). Hal ini terlihat ketika Allah S.W.T. mengharamkan khamar tidak dilakukan secara langsung, melainkan secara bertahap, karena minum khamar ketika itu sudah menjadi kebiasaan masyarakat sebelum Islam (Arief, 2002). Oleh karena itu untuk merubah perilaku yang sudah menjadi kebiasaan tidak bisa dilakukan secara langsung, melainkan harus secara bertahap.

Pembiasaan akan efektif jika pembiasaan dilakukan sejak dini dan di lakukan secara terus menerus (Ihsani et al., 2018). Pendapat lain menjelaskan, pembiasaan harus diiring dengan suri tauladan, adanya pengawaan, dilakukan secara bertahap dan didukung oleh lingkungan (Ramdhani, 2017). 


\section{Ibadah}

Islam memiliki beberapa ajaran pokok, salah satu diantaranya adalah ibadah. Ibadah memiliki peran sangat penting dalam Islam, karena ibadah merupakan akutualisasi dari keimanan dan merupakan tugas utama manusia diturunkan ke muka bumi (Q.S. Adz-Dzaariyaat 51:56):

Kata ibadat atau ibadah diambil dari bahasa Arab dari kata "ibadah". Secara etimologi kata ibadah diambil dari kata abada, ya'budu, ibadatan yang berarti menyembah, memuja, mengabdi atau menghamba (Kallang, 2018). Ibadah juga dapat berarti tunduk, patuh, merendahkan diri atau meghambakan diri (Said, 2017). Pendapat lain menjelaskan, secara etimologi kata ibadah yang merupakan bentuk masdar dari kata abada memiliki dua makna. Pertama, ibadah bermakna lin wa zull berarti kelemahan dan kerendahan. Kedua ibadah bermakna syiddat wa qilazh yang berarti kekerasan dan kekasaran (Kallang, 2018). Ibadah merupakan aktualisasi dari kecintaan kepada Allah disertai dengan ketundukan, kepatuhan dan merendahkan diri kepadaNya (Kastolani, 2016). Orang yang melakukan ibadah disebut 'abid, sedangkan Yang dipuja atau Yang disembah disebut ma'bud (Kallang, 2018). Dalam kamus Besar Bahasa Indonesia, ibadah berarti suatu pernyataan atau perbuatan yang dilakukan berdasarkan ajarn agama untuk berbakti kepada Allah atau Tuhan (Tim Penyusun Kamus Pusat Bahasa, 2016).

Secara terminilogi, ulama fikih mengatakan, ibadah berarti semua amal perbuatan yang dilakukan untuk mendapatkan keredaan dan pahala dari Allah (Said, 2017). Sementar ulama tauhid menjelaskan, ibadah berarti meng-Esakan Allah S.W.T. dan tidak menyekutukan dengan sesuatu yang lain (Kastolani, 2016).

Ulama tasawuf mengartikan ibadah sebagai suatu perbuatan yang dilakukan oleh orang yang sudah mukalaf guna mengendalikan hawa nafsunya untuk mengagungkan dan mendekatkan diri kepada Allah (Kallang, 2018). Sementara ulama akhlak mengartikan ibadah sebagai amal perbuatan yang dilakukan dalam rangka melaksanakan perintah Allah dan menjauhi larangan-Nya guna untuk menegakkan syariat-Nya (Said, 2017)

Menurut ulama tafsir, ibadah merupakan suatu bentuk kepatuhan, ketundukan dan ketaatan sebagai dampak dari adanya keyakinan dan rasa pengagungan seseorang kepada Sang Khalik (Shihab, 1999). Abd Muin menjelaskan, ibadah merupakan ungkapan cinta, ketaatan dan kekhuatiran seorang hamba kepada Sang Khalik, kekhuatiran yang dimaksud di sini adalah kekhuatiran hamba akan adanya 
penolakan Sang Khalik terhdapnya (Salim, 1999)

Beberapa terminologi ibadah sebagaimana telah diuraikan, sepintas berbeda, namun memiliki esensi yang sama. Ibadah pada hakekatnya adalah pengabdian seorang hamba kepada Sang Khalik yang dilakukan dengan cara mengagungkan-Nya, mencintai-Nya, tunduk kepada-Nya, mentaati perintah-Nya dan menjauhi larangan-Nya.

Dilihat dari segi pelaksanaannya ibadah dapat dikelompokkan menjadi tiga. Pertama ibadah hati, seperti mahabbah atau cinta, raja' atau megharap, ikhlas, tawakal, takut dan sebagainya. Kedua, ibadah lisan dan hati, seperti zikir, tahlil, tahmid, bersyukur, berdoa, membaca al Quran dan sebagainya. Ketiga, ibadah fisik dan hati, seperti shalat, puasa, zakat, haji, berjihad dan sebagainya (Raya \& Mulia, 2016).

Pendapat lain menjelaskan, secara garis besar ibdaha dapat dibagi menjadi dua, yaitu ibadah khassah atau ibadah mahdah dan ibadah 'ammah atau ghoitu mahdah. Ibadah khassah atau khusus atau ibadah mahdah adalah suatu ibadah yang ketentuan, waktu, kadarnya dan tata cara pelaksanaannya sudah ditetapkan dan diatur secara rinci oleh Allah dan Rasul-Nya di dalam nash, seperti sholat, puasa, zakat, haji dan sebagainya (Raya \& Mulia, 2016). Ibadah 'ammah atau umum atau ghoiru mahdah merupakan segala sesuatu yang dilakukan dengan niat semata-mata karena Allah dan mendatangkan kebaikan, namun tempat, waktu dan tata cara pelaksanaannya tidak diatur secara rinci, seperti makan, minum, bekerja, belajar, megajar, tolong menolong dan sebagainya (Raya \& Mulia, 2016).

Ibadah mahdhah pada dasarnya harus dilaksanakan oleh setiap orang yang sudah mukallaf tanpa terlebih dahulu harus megkaji makna dan sebabnya, dilaksanakan secara ikhlas dan harus mencontoh Rasulullah SAW (Raya \& Mulia, 2016).. Berbeda dengan ibadah ghoiru mahdhah, ada lima hal yang dapat dijaikan acuan. Pertama, dilaksanakan secara ikhlas, Kedua, tidak ada dalil yang melarang. Ketiga, pelaksanaannya dibolehkan tidak sama persis dengan yang dicontohkan Rasulullah S.A.W. Keempat, harus logis. Kelima, bermanfaat (Raya \& Mulia, 2016).

\section{METODE}

Penelitian ini merupakan penelitian kualitatif, yaitu salah satu jenis penelitian yang berupaya mengungkapkan berbagai fenomena yang dialami oleh objek penelitian secara alamiah. Penelitian ini akan mengungkapkan implementasi teori operant conditioning untuk membiasaikan siswa dalam melaksanakan ibadah. Sumber 
data penelitian adalah kepala sekolah, guru dan siswa SMPIT Rabbi Radhiyya Curup.

Teknik pengumpulan daya yang digunakan adalah wawancara tidak trstruktur. Wawancara tidak terstuktur adalah salah satu jenis wawancara dimana peneliti tidak memggunakan pedoman wawancara secara rinci, melainkan hanya menggunakan pedoman wawancara yang memuat pokok-pokok pikiran terkait masalah yang akan diteliti.

Teknik keabsahan data yang digunakan adalah trianggulasi sumber. Triangulasi sumber merupakan teknik keabsahan data yang dilakukan dengan mengumpulkan data dari berbagai sumber menggunakan teknik pengumpulan data yang sama. Data yang terkumpul kemudian dianalisi dengan menggunakan model analisis Miles dan Huberman. Model analisis data ini terdiri dari tiga tahap, yaitu reduksi data, penyajian data dan penarikan kesimpulan.

\section{PEMBAHASAN}

\section{Jenis-jenis Ibadah}

Sekolah Menengah Pertama Islam Terpadu (SMPIT) Rabbi Radhiyya Curup memiliki beberapa program keagamaan guna untuk meningkatkan pemahaman dan kemampuan siswa dalam mengamalkan nilai-nilai keislaman dalam kehidupan sehari-hari, baik dalam aspek akidah, ibdah maupun akhlak. Khusus di bidang ibadah, ada beberapa progam keagamaan yang manjadi unggulan, yaitu shalat wajib berjamaan, shalat sunat, tahsin, tahfiz dan puasa sunat. Hal ini harus ditegakkan ke atas berdasarkan kalimat tauhid "lâ ilâha illallâh muhammad rasûlllâh" (Saihu, 2019: 189), serta sejalan dengan hasil wawancara dengan kepala sekolah sebagai berikut :

SMPIT Curup memiliki beberapa program unggulan di bidang keagamaan dalam rangka untuk membentuk generasi yang unggul dan Islami. Secara garis besar program keagamaan tersebut dapat dibagi menjadi tiga yaitu penguatan bidang akidah, ibadah dan akhlak. Di bidang ibadah ada beberapa program unggulan, yaitu pembiasaan sholat berjamaan, shalat sunat, tahsin, tahfiz dan puasa sunat (Agus Suryadi, wawancara pribadi, 02 November 2019).

Menurut Reni Puspitasari (wawancara pribadi, 02 November 2019) siswa diharuskan melaksanakan shalat wajib lima waktu sehari semalam secara berjamaah, khusus shalah zohor dan ashar wajib dilaksanakan secara berjamaah di sekolah, sedangkan untuk shalat magrib, isya dan subuh dilaksanakan berjamaah di rumah, di mushalla atau di masjid di bawah pengawasan orang tua. Lebih lanjut Riri Hutami (wawancara Pribadi, 02 November 2019) menjelaskan siswa juga dibiasakan untuk melaksanakan shalat sunat, seperti 
shalat sunat rawatib, shalat duha dan shalat tahajjud. Pada jam sekolah, shalat sunat rawatib sebelum dan sesudah zohor, sebelum ashar dan shalat duha dilaksanakan di sekolah.

Selain itu, siswa juga dibiasakan untuk shalat tahajjud melalui kegiatan MABIT (Malam Bina Iman dan Takwa) yang dilaksanakan setiap sebulan sekali (Indra, wawancara pribadi, 02 November 2019). Siswa juga diwajibkan untuk mengikuti program tahsin yang dilaksanakan setiap hari selama 15 menit sebelum pembelajaran dimulai dan mengikuti program tahfiz minimal juz 30 siswa harus hafal sebelum menamatkan studi di SMPIT Rabbi Radhiyya Curup (Rudi Irawan, wawancara pribadi, 03 November 2019). Perogram kegiatan keagamaan dilakukan untuk membiasakan siswa melaksanakan pusa sunat, seperti puasa sunat senin kamis yang dilaksanakan dua minggu sekali dalam setiap bulan, dan puasa suant hari arofah di bulan dzulhijjah (Sandra Salfira, wawancara pribadi, 03 November 2019).

Berbagai program keagamaan, termasuk program keagamaan pada aspek ibadah, bukan hanya diwajibkan kepada siswa, melainkan juga diharuskan kepada semua gura yang ada di lingkungan SMPIT Rabbi Radhiyya Curup. Guru bukan hanya berkewajiban memberikan bimbingan, arahan, motovasi dan memberi contoh, tetapi harus mampu menjadi contoh bagi peserta didiknya (Indra, wawancara pribadi, 02 November 2019).

Setiap setahun sekalin dilakukan evaluasi terhadap tahsin dan tahfiz para ustaz dan ustazah. Evaluasi tersebut bertujuan untuk mengetahui peningatan kualitas dan kuantitas tahsin dan tahfiz seluruh ustaz dan uztazah yang mengajar di SMPIT Rabbi Radhiyya Curup. Dengan adanya program ini diharapkan selogan guru bukan dituntut hanya mampu memberi contoh, melainkan harus menjadi contoh benar-benar bisa terwujud (Agus Suryadi, wawancara pribadi, 02 November 2019).

Sekolah merupakan lembaga pendidikan formal yang berfungsi untuk mengembangkan potensi akademik maupun non akademik (Firdianti, 2018). Di sisi lain, sekolah juga berfungsi untuk mengajar, membimbing dan melatih siswa agar memiliki pengetahuan, wawasan, sikap, kebiasaan dan perilaku yang baik serta keterampilan untuk mempersiapkan diri di masa depan (Hanafi et al., 2019). Mengingat, banyak sekolah yang melaksanakan pembelajaran dengan sistem full day school dan boarding school serta adanya kesibukan orang tua, sehingga mengurangi waktu dan kesempatan bagi orang untuk mendidikan anaknya khususnya 
dalam pembiasaan menjalankan ibadah. Berbagai program dalam pembiasaan sebagaimana dilaksanakan di SMPIT Rabbi Radhiyya Curup merupakan salah satu solusi untuk membantu orang tua dalam mendidikan anak pada aspek ibadah.

\section{Pola pembiasaan}

Ibadah memiliki peran yang sangat penting dalam kehidupan beragama. Sebaik apapun keimanan seseorang, tetapi tidak melakukan ibadah secara baik dan benar, maka keimanan seseorang tersebut perlu ditingkatkan dan diaktualisasikan melalui amal saleh dalam bentuk ibadah. Ibadah yang baik selain harus dilakukan berdasarkan keimanan, dipahami dan sesuai dengan ketentuan syariat, juga harus diamalkan dalam kehidupan sehari-hari. Pengamalan ibadah secara konsisten dan kontiniu bukan serta merta muncul dengan sendirinya, melainkan perlu adanya pembiasaan. Di SMPIR Rabbi Radhiyya Curup memiki pola tersendiri untuk membiasakan siswa dalam melakukan ibadah. Pola pembiasaan diawali dengan pemberian pemahaman kepda siswa, diikuti dengan menumbuhkan minat dan diiring dengan pembiasaan untuk melakukan ibadah dalam kehidupan sehari-hari. Hal ini sejalan dengan hasil wawancara sebagai berikut:

Pola pembiasaan yang dilakukan di SMPIT Rabbi Radhiyya Curup dilakukan melalui tiga rangkaian kegiatan.
Pertama, peningkatan pengetahuan dan pemahaman siswa tentang ibadah baik secara teoritis maupun secara praktis. Hal ini bertujuan agar ibadah yang dilakukan sesuai dengan ketentuan syariat. Kedua, membangun kesadaran dan memotivasi siswa untuk melakukan ibadah. Ketiga, melakukan pembiasaan (Agus Suyradi, wawancara pribadi, 02 November 2019).

Menurut Reni Puspitasari (wawancara pribadi, 04 November 2019), peningkatan pengetahuan dan pemahaman siswa baik secara teorits maupun praktis tentang ibadah dilakukan melalui kegiatan pembelajaran pada mata pelajaran Tahsin, Tahfiz, Fikih, Quran Hadis dan Akidah Akhlak. Dalam pembelajaran tersebut dibahas bagi materi terkait dengan ibadah secara teoritis maupun praktis, mulai dari tajuwid, taharah, shalat, puasa dan sebagainya. Rini Hutami, (wawancara pribadi 04 November 2019) menjelaskan, untuk memotivasi dan membangun kesadaran siswa dilakukan kegiatan mentoring. Kegiatan mentorig pada dasarnya adalah kegiatan bimbingan atau pemberian arahan yang dilakukan oleh guru pembimbing, wali kelas, kakak senior atau mendatangkan model dari luar sekolah guna memberikan arahan, bimbingan dan memotivasi siswa untuk meningkatkan prestasinya, termasuk dalam melaksanan kegiatan keagamaan aspek ibadah. Kegiatan mentoring ini dilakukan seminggu sekali, 
setiah hari sabtu (Indra, wawancara pribadi, 03 November 2019).

Pembiasaan ibadah dilakukan dengan cara mempraktekkan secara langsung berbagai ibadah yang sudah diajarkan dan menjadi program khusus sekolah secara langsung, baik di sekolah maupun di rumah secara terus-menerus (Rudi Irawan, wawancara pribadi, 03 Novemver 2019). Kegiatan tersebut dilakukan di bawah bimbingan, arahan, pengawasan ustaz dan orang tua. Para ustaz dan ustazah, harus mempu menjadi contoh dan suri tauladan bagi siswa dalam pembiasaan ibadah. Oleh karena itu di SMPIT Rabbi Radhiyya Curup, yang dituntut untuk mengerjakan shalat berjamaah, shalat sunat, puasa sunat, membaca dan menghafal ayat al Quran bukan hanya siswa melainkan diharuskan kepada para ustaz dan ustazah (Agus Suryadi, wawancara pribadi, 05 November 2019).

Ada tiga aspek penting terkait dengan pola pembiasaan dalam membangun karakter siswa, yaitu knowing atau pengetahuan, feeling atau perasaan atau keinginan dan doing atau tindakan (Annur, 2016; Arofah, 2017; Julaeha, 2019). Siswa harus diberikan pemahaman yang terkait dengan nilai-nilai yang akan dibiasakan. Pemberian pemahaman dapat dilakukan melalui kegiatan pembelajaran, buku, diskusi, pamplet, brosur dan sebagainya. Selain pemahaman, siswa juga perlu dimotivasi agar muncul minat dan keinginan untuk melaksanakan nilai-nilai yang akan dibisakan. Dengan adanya pemahaman, minat dan keinginan, maka pembiasaan akan lebih mudah dilaksanakan.

Banycak cara yang dapat dilakukan untuk membiasakan siswa dalam bersikap dan berperilaku, termasuk membiasakan siswa beribadah. Melakukan sesuatu secara berulang-ulang dinilai sebagai metode yang efektig dalam membiasakan siswa (Ahsanulkhaq, 2019; Nadar, 2019). Pembiasaan dapat juga dilakukan dengan memberikan keteladanan (Angdreani et al., 2020; Hendriana \& Jacobus, 2017) dan dilakukan melalui kegiatan mentoring.

\section{Reinforcement}

Pembiasaan merupakan salah satu proses yang dilakukan dalam membentuk sikap dan perilaku yang sifatnya relatif menetap. Proses pembiasaan dapat dilakukan dengan mengerjakan sesuatu secara berulang-ulang baik secara sendiri maupun secara bersama-sama, secara terjadwal atau tidak terjadwal, di sekolah maupun di luar sekolah. Pembiasaan dapat digunakan sebagai salah satu metode untuk membentuk kebiasaan bersikap dan berperilaku seseorang, termasuk dalam kebiasaan dalam menjalankan ibadah. 
Kebiasaan dalam menjalankan ibadah perlu ditanamkan mulai sejak dini, agar ketika dewasa individu dapat menjalankan ibadah secara konsisten dan istiqomah. Dalam teori operant conditioning, salah satu aspek penting untuk melakukan pembiasaan adalah pemberian reinforcement. Begitu juga halnya di SMPIT Rabbi Radhiyya Curup, pemberian reinforcement juga diterapkan untuk membiasakan siswa dalam melaksanakan ibadah. Agus Suryadi dan Indra menjelaskan sebagai berikut:

Siswa-siswi yang mendapatkan prestasi tertentu, baik di dalam maupun di luar pembelajaran, biasanya diberikan reinforcement berupa reward. Reward juga diberikan kepada siswa yang memiliki prestasi dalam pelaksanaan prorgam khusus di bidang keagamaan, termasuk pada aspek ibadah. Reward biasanya diberikan setiap satu semester sekali ketika pembagian rapor. Reward tersebut berupa sertifikat dan bingkisan diberikan kepada satu orang siswa atau siswi yang terbaik pada setiap kelas dalam pelaksanaan program keagamaan (Agus Suryadi, wawancara pribadi 05 November 2019).

Penetapan siswa dan siswi terbaik dalam kegiatan program khusus dilakukan oleh wali kelas berdasarkan rekomenadri dari ustaz atau ustazah pengelola program khusus. Pemberian reward atau penghargaan berupa sertifikat atau bingkisan bisanya dilakukan di setiap akhir semester ketika pembagian rapor. Reward juga adakalanya berbetuk pemberian nilai yang baik bagi yang berprestasi, diizinkan melanjutkan kegiatan selanjutnya, dijadikan model bagi teman-temannya, diutus untuk mengikuti perlobaan dan sebagainya

(Indra, wawancara pribadi, 09 November 2019).

Pemberian reward atau penghargaan pada dasarnya bukan sasaran akhir yang harus dicapai oleh siswa, melainkan hanya sekedar untuk memotivasi, agar siswa lebih giat dan rajin dalam melaksanakan kegiatan program khusus bidang keagaman, khsusnya pada aspek ibadah (Reni Puspitasari, wawacara pribadi, 06 November 2019). Siswa sangat senang ketika mendapat reward atau penghargaan dari sekolah ketika menjadi siswa terbaik dalam bidang tafiz al Quran (Khalis Dzahab, wawancara pribadi, 09 November 2019). Hal senada juga dikemukakan oleh Bunga Istiqaman (wawancara pribadi, 09 November 2019), ia juga merasa senang mendapat reward ketika menjadi siswi terbaik dalam bidang tahsin al Quran. Namun reward atau penghargaan bukan menjadi tujuan utama dalam mengikuti kegiatan program khusus bidang keagamaan. Pembentukan sikap dan kebiasaan yang baik dalam menjalankan ibadah jaug lebih penting dari segalanya.

Menurut teori operan conditioning, pembiasaan dapat dilakukan dengan pemberian reinforcement (Hardhi \& Sudrajat, 2018; Lisnawati, 2016). Reinforcemen dapat berbentuk reward atau penghargaan, baik secara verbal maupun non verbal (Ernata, 2017). Reward secara 
verbal seperti dengan ucapan baik, bagus, lanjutkan dan sebagainya. Reward non verbal dapat berbetuk anggukan, senyum, gestur tubuh, sertifikan dan benda-benda tertentu. Tujuan utama pemberian reward untuk memberikan motovasi agar siswa lebih semangat dalam melaksanakan berbagai kegiatan untuk membentuk kebiasaan siswa.

\section{Punishmant}

Teori operant conditioning yang diterapkan di SMPIT Rabbi Radhiyya Curup dalam membiasakan siswa beribadah selanjutnya adalah punishmant atau hukuman. Punishmant diberikan kepada siswa yang melanggar ketentuan terkait dengan berbagai program kegiatan di sekolah, termasuk pelaksanaan kegiatan progam khusus bidang keagamaan. Punishmant yang berikan kepada siswa bukan berupa hukuman fisik, melainkan hukuman yang bersifat mendidik dan memberikian manfaat bagi siswa. Rudi Irawan menjelaskan sebagai berikut:

Punishmant atau hukuman diberikan kepada siswa yang melanggar ketentuan. Tujuan pemberian punishmant agar siswa komitmen dan disiplin dalam menjalankan ketentuan yang ada. Punishmant yang diberikan berisfat mendidik, seperti menulis ayat al Quran, menghafal ayat, menghafat asmalul husna, membimbing teman sebayan dan sebagainya (Rudi Irawan, wawancara pribadi, 05 November 2019).
Pemberian punishmant biasanya diberikan oleh ustaz atau ustazah yang mengkoordinir masing-masing kegiatan program khusus kepada siswa yang melanggar ketentuan. Beberapa pelanggaran tersebut diantaanya tidak mengikuti tahsin, tidak murojoaah tepat waktu, tidak menambah hafalan tepat waktu, tidak puasa senin kamis sesuai dengan ketentuan yang disepakai tanpa alasan yang jelas, dan sebagainya (Riri Hutami, wawancara pribadi, 04 November 2019).

Siswa yang mendapatkan punishmant sebanyak 3 (tiga) kali berturut-turut dalam kasus yang sama, namun belum terjadi perubahan maka akan dilimpahkan ke wali kelas untuk diberikan bimbingan dan arahan (Reni Puspitasari, wawancara pribadi, 05 November 2019). Setelah diberikan bimbingan dan arahan belum ada perubahan, maka akan dilimpahkan kepada Guru Pembimbing untuk diberikan layanan khusus. Jika belum ada perubahan juga maka dipanggil wali siswa untuk membicarakan permasahan yang dialami oleh siswa (Indra, wawancara pribadi, 09 November 2019).

Berdasarkan keterangan Sandra Salfira, wawancara pribadi, 03 November 2019), jarang sekali ada siswa yang mendapatkan punishmant sebanyak tiga kali berturut akibat melakukan pelanggaran pada program khusus. Hal ini disebabkan karena 
pihak sekolah sejak awal sudah mensosialisasikan kepada siswa dan wali siswa (Agus Suryadi, wawancara pribadi, 05 November 2019). Di sisi lain, sekolah juga menjalin kerja sama dengan wali siswa agar ikut bekerja sama membimbing, memantau dan memperhatikan anaknya untuk menyukseskan semua program yang dicanangkan pihak sekolah (Rini Hutami, wawancara pribadi, 02 November 2019).

Punishmant atau hukuman merupakan salah satu unsur yang dapat diterapkan untuk pembiasaan sikap dan tingkah laku. Punishmant pada dasarnya adalah untuk memotivasi dalam pembentukan sikap, perilaku dan karakter siswa (Febianti, 2018; Ikranagara, 2015). Oleh karena itu, punishmant yang diberikan adalah punishmant yang mendidik seperti membaca, menghafal, menulis ayat al Quran, membantu teman dan sebagainya, bukan yang bersifat fisik atau bertujuan untuk menyakiti. Studi menunjukkan, punishmant bersifat fisik kurang efetif untuk memotivasi sisiwa (Sujiantari et al., 2016). Punishmant secara fisik harus dihindari (Firdaus, 2020), karena implikasinya adalah fisik siswa menjadi sakit dan bisa menimbulkan tekanan psikologis sehingga siswa malas belajar, bahkan dapat menyebabkan timbulnya aspek hukum bagi guru.

\section{E. KESIMPULAN}

Beberapa program khusus terkait dengan pembiasaan siswa dalam melaksanakan ibadah yang dilaksanakan di SMPIT Rabbi Radhiyya Curup adalah shalat wajib berjamaah, shalat sunat rawatib, shalat duha, shalat tahajjud, puasa sunat Senin Kamis, puasa sunat hari Arofah, tahsin dan tahfiz.

Pola pembiasan dilakukan melalui tiga tahap, yaitu knowing, feeling dan doing. Teori operant conditioning, yang diimplementasikan untuk membiasakan siswa melaksanakan ibadah diantaranya adalah pemberian reward dan punishmant. Reward diberikan kepada siswa yang memiliki prestasi. Punishmant diberikan kepada siswa yang tidak melaksankaan kegiatan program khusus yang telah disepakati. Punishmant yang diberikan bersifat mendidik, dan bukan dalam bentuk fisik. Pembiasaan juga didukung suri tauladan yang ditampilkan oleh ustaz dan ustazah dan kegiatan mentoring. 


\section{DAFTAR PUSTAKA}

Afandi, N. K. (2017). Learning Motivation: Reward and Punishment in The Western and The Islamic Perspective. In International Seminar On Islamic Education.

Ahsanulkhaq, M. (2019). Membentuk Karakter Religius Peserta Didik Melalui Metode Pembiasaan. Jurnal Prakarsa Paedagogia, 2(1).

Aini, H., Suandi, N., \& Nurjaya, G. (2019). Pemberian Penguatan (Reinforcement) Verbal dan Nonverbal Guru dalam Pembelajaran Bahasa Indonesia di Kelas VII MTsN Seririt. Jurnal Pendidikan Bahasa dan Sastra Indonesia Undiksha, 8(1): Article 1. https://doi.org/10.23887/jjpbs.v8i1.202 46

Alfiah, L. (2018). Pembentukan Karakter Religius Anak Melalui Metode Pembiasaan di MI Negeri 1 Banyumas Kabupaten Banyumas [PhD Thesis]. IAIN.

Angdreani, V., Warsah, I., \& Karolina, A. (2020). Implementasi Metode Pembiasaan: Upaya penanaman nilainilai islami siswa SDN 08 Rejang Lebong. At-Ta'lim: Media Informasi Pendidikan Islam, 19(1): 1-21.

Annur, F. (2016). Pendidikan Karakter Berbasis Keagamaan (studi kasus di SDIT Nur Hidayah Surakarta). AtTarbawi: Jurnal Kajian Kependidikan Islam, 1(1): 39-56.

Arief, A. (2002). Pengantar Ilmu dan Metodologi Pendidikan Islam. Ciputat Press.

Arofah, L. (2017). Pentingnya Siswa Memiliki Self Discipline Sebagai Alternatif Penguatan Karakter. Seminar Nasional Bimbingan Konseling Universitas Ahmad Dahlan, 2.
Asfar, A. M. I., Asfar, A. M., \& Halamury, M. (2019). TEORI BEHAVIORISME (Theory of Behaviorism). https://doi.org/10.13140/RG.2.2.34507. 44324

Cahyaningrum, E. S., Sudaryanti, S., \& Purwanto, N. A. (2017). Pengembangan Nilai-nilai Karakter Anak Usia Dini Melalui Pembiasaan dan Keteladanan. Jurnal Pendidikan Anak, 6(2): 203-213. https://doi.org/10.21831/jpa.v6i2.1770 7

Ernata, Y. (2017). Analisis motivasi belajar peserta didik melalui pemberian reward dan punishment di sdn ngaringan 05 kec. Gandusari kab. Blitar. Jurnal Pemikiran Dan Pengembangan Sekolah Dasar (JP2SD), 5(2): 781-790.

Faozan, F. A., Maya, R., \& Sarifudin, S. (2019). Peran Pembimbing Asrama (Musyrif) dalam Meningkatkan Disiplin Beribadah Santri di Mahad Huda Islami (MHI) Tamansari Kabupaten Bogor. Prosa PAI: Prosiding Al Hidayah Pendidikan Agama Islam, 2(1): 78-88.

Febianti, Y. N. (2018). Peningkatan Motivasi Belajar Dengan Pemberian Reward And Punishment Yang Positif. Edunomic: Jurnal Ilmiah Pendidikan Ekonomi Fakultas Keguruan dan Ilmu Pendidikan, 6(2): 93-102.

Firdaus, F. (2020). Esensi Reward dan Punishment dalam Diskursus Pendidikan Agama Islam. Jurnal Pendidikan Agama Islam Al-Thariqah, 5(1): 19-29. https://doi.org/10.25299/althariqah.2020.vol5(1).4882

Firdianti, A. (2018). Implementasi Manajemen Berbasis Sekolah dalam Meningkatkan Prestasi Belajar Siswa. Yogyakarta: Gre Publishing.

Firmansyah, F. (2018). Internalisasi NilaiNilai PAI melalui Metode Pembiasaan 
pada Siswa MTs. Al-Kautsar Ranggo. AL-FURQAN, 6(2), 1-12.

Hambali, M., \& Yulianti, E. (2018). Pengaruh Ekstrakurikuler Keagamaan terhadap Pembentukan Karakter Religius Peserta Didik di Kota Majapahit. Pedagogik: Jurnal Pendidikan, 5(2): 193-208. https://doi.org/10.33650/pjp.v5i2.380

Hanafi, M., Suciati, \& Iswahyudi, D. (2019). Peran Guru dalam Membina Moral Siswa di Sekolah Menengah Pertama. Prosiding Seminar Nasional Fakultas Ilmu Pendidikan, 3: 122-129.

Harahap, M. Y., Lubis, M., \& Hanafiah, M. A. (2019). Strategi Penanaman Kebiasaan Beribadah Pada Anak (Studi Kasus Pada Masyarakat Muslim Minoritas Desa Kuta Gugung Kabupaten Karo). Intiqad: Jurnal Agama dan Pendidikan Islam, 11(2): 324-343.

Hardhi, T. R., \& Sudrajat, A. (2018). The Reinforcement of The Character Values in The History Subject at SMA Negeri 1 Kota Yogyakarta. ISTORIA: Jurnal Pendidikan dan Sejarah, 14(2).

Hendriana, E. C., \& Jacobus, A. (2017). Implementasi pendidikan karakter di sekolah melalui keteladanan dan pembiasaan. JPDI: Jurnal Pendidikan Dasar Indonesia), 1(2): 25-29.

Hidayatullah, A. S. H. A. S. (2019). Pengembangan Budaya Religius Melalui Kegiatan Pembiasan Komisariat IPNU di MTs Ma'arif NU 1 Cilongok Kecamatan Cilongok Kabupaten Banyumas. Dwija Inspira: Jurnal Pendidikan Multi Perspektif, 2(2): 209-224.

Hindayati, S. M., \& Mayasari, D. (2019). Efektifitas Metode Reinforcement Guna Meningkatkan Motivasi Belajar pada Siswa Kelas X SMK-S al Kaaffah Kepanjen. $\quad H E L P E R \square$ : Jurnal
Bimbingan dan Konseling, 36(1): 1-6. https://doi.org/10.36456/helper.vol36.n o1.a2816

Ihsani, N., Kurniah, N., \& Suprapti, A. (2018). Hubungan Metode Pembiasaan dalam Pembelajaran dengan Disiplin Anak Usia Dini. Jurnal Ilmiah Potensia, 3(1): 256512. https://doi.org/10.33369/jip.3.2.105110

Ikranagara, P. (2015). Pemberian Reward Dan Punishment Untuk Meningkatkan Kedisiplinan Siswa dalam Pembelajaran IPS Kelas V SD Negeri 1 Kejobong Purbalingga. BASIC EDUCATION, 4(2).

Is, S. S. (2018). Pembinaan Guru Pai dalam Membiasakan Siswa Melaksanakan Shalat Berjamaah. Tarbawi: Jurnal Pendidikan Agama Islam, 3(01): 66-78.

Julaeha, S. (2019). Problematika Kurikulum Dan Pembelajaran Pendidikan Karakter. Jurnal Penelitian Pendidikan Islam,[SL], 7(2): 157-182.

Kallang, A. (2018). Konteks Ibadah Menurut Al-Qur'an. Al-Din: Jurnal Dakwah dan Sosial Keagamaan, 4(2): Article https://doi.org/10.35673/ajdsk.v4i2.630

Kastolani, K. (2016). Ibadah Ritual dalam Menanamkan Akhlak Remaja. INJECT: Interdisciplinary Journal of Communication, 1(2): 127-144. https://doi.org/10.18326/inject.v1i2.12 7-144

Kausar, A., \& Suyadi, S. (2020). Problematika Motivasi Belajar dalam Teori Operant Conditioning pada Pembelajaran PAI di SDN Nogopuro Sleman. Jurnal Pendidikan Dasar dan Keguruan, 5(2), 1-8. https://doi.org/10.47435/jpdk.v5i2.398

Keikazeria, V. M., \& Ngare, F. (2020). Komunikasi Interpersonal Ibu dan Anak dalam Pembentukan Karakter 
Beribadah Anak. Jurnal Communio: Jurnal Jurusan Ilmu Komunikasi, 9(2): 1613-1629.

Kholisotin, L., \& Minarsih, M. (2018). Implementasi Ekstrakurikuler Keagamaan di SMKN-1 Palangka Raya. Anterior Jurnal, 18(1): 71-78. https://doi.org/10.33084/anterior.v18i1. 435

Lisnawati, S. (2016). The Habituation of Behavior as Students' Character Reinforcement in Global Era. Jurnal Pendidikan Islam UIN Sunan Gunung Djati, 2(3): 413-428.

Ma`arif, M. A. (2018). Analisis Strategi Pendidikan Karakter Melalui Hukuman Preventif. Ta'allum: Jurnal Pendidikan Islam, $\quad 6(1)$ : $31-56$. https://doi.org/10.21274/taalum.2018.6. $1.31-56$

Ma'arif, M. A. (2017). Hukuman (Punishment) dalam Perspektif Pendidikan di Pesantren. Ta'allum: Jurnal Pendidikan Islam, 5(1): 1-20. https://doi.org/10.21274/taalum.2017.5. $1.1-20$

Makki, A. (2018). Peningkatan Efektifitas Pembelajaran Melalui Remedial (Telaah Kritis Teori Belajar Burrhus Frederick Skinner). Jurnal Studi Islam: Pancawahana, 13(2): 102-109.

Muazzaroh, F. (2017). Reaktualisasi Pendidikan Behavioristik. Syaikhuna: Jurnal Pendidikan dan Pranata Islam, 8(2): 265-286.

Muktar, M. (2019). Pendidikan Behavioristik dan Aktualisasinya. TABYIN: JURNAL PENDIDIKAN ISLAM, 1(1): 14-30.

Nadar, W. (2019). Peningkatan Kedisiplinan Anak Usia Dini Melalui Metode Pembiasaan Token Economy. ElementerIs: Jurnal Ilmiah Pendidikan Dasar Islam, 1(1): 1-11.
Nahar, N. I. (2016). Penerapan teori belajar behavioristik dalam proses pembelajaran. NUSANTARA: Jurnal Ilmu Pengetahuan Sosial, 1(1).

Nata, A. (2016). Ilmu Pendidikan Islam. Prenada Media.

Purwanto, M. N. (2018). Psikologi Pendidikan. Remaja Rosdakarya.

Raharjo, T., Rohana, H., Istyarini, I., \& Nurussaadah, N. (2018). Pengaruh Full Day School terhadap Pembentukan Karakter Religius Siswa. Indonesian Journal of Curriculum and Educational Technology Studies, 6(1), 22-32.

Rahim, A., \& Setiawan, A. (2019). Implementasi Nilai-nilai Karakter Islam Berbasis Pembiasaan Siswa di Madrasah Tsanawiyah Negeri Kota Batu. SYAMIL: Jurnal Pendidikan Agama Islam (Journal of Islamic Education), $\quad$ 7(1): 49-70. https://doi.org/10.21093/sy.v7i1.1715

Ramadhan, R. S. (2020). Pengaruh Reinforcement Negatif dan Positif terhadap Motivasi Siswa dalam Pembelajaran Servis Atas Bolavoli. Jurnal Pendidikan Olahraga dan Kesehatan, 8(1): Article 1. https://jurnalmahasiswa.unesa.ac.id/ind ex.php/jurnal-pendidikanjasmani/article/view/35309

Ramdhani, M. A. (2017). Lingkungan Pendidikan dalam Implementasi Pendidikan Karakter. Jurnal Pendidikan UNIGA, 8(1): 28-37.

Ratnawati, E. (2016). Kajian Psikologis Tentang Pendekatan Teori Reinforcement dalam Proses Pembelajaran. Edueksos: Jurnal Pendidikan Sosial \& Ekonomi, 4(1): Article 1. https://www.syekhnurjati.ac.id/jurnal/i ndex.php/edueksos/article/view/651 
Raya, A. T., \& Mulia, S. M. (2016). Menyelami Seluk Beluk Ibaddah dalam Islam. Kencana.

Rianita, T., Hidayati, Y., Rosidi, I., \& Muharrami, L. K. (2018). Pengaruh Model Pembelajaran Murder Dengan Teori Pembiasaan Perilaku B.F Skinner Terhadap Kemandirian Belajar Siswa. Natural Science Education Research, 1(1): 40-48.

Rufaedah, E. A. (2018). Teori Belajar Behavioristik Menurut Perspektif Islam. Risâlah: Jurnal Pendidikan dan Studi Islam, $\quad 4(1)$ : 13-30. https://doi.org/10.31943/jurnal_risalah. v4i1.60

Rusady, N. P., Nur Amalia, S. S., \& Teach, M. (2017). Pembiasaan Shalat Dhuha Dalam Pembentukan Karakter Mandiri Beribadah Siswa Kelas III MI Muhammadiyah PK Kartasura Tahun Ajaran 2016/2017 [PhD Thesis]. Universitas Muhammadiyah Surakarta.

Said, S. (2017). Wawasan Al-Qur'an tentang Ibadah. DIKTUM: Jurnal Syariah dan Hukum, 15(1): 43-54. https://doi.org/10.28988/diktum.v15i1. 424

Saihu. (2019). Pendidikan Karakter Berbasis Kearifan Lokal (Studi di Jembrana Bali). Edukasi Islami: Jurnal Pendidikan Islam, 08(01).

Saihu. (2019). Urgensi 'Urf dalam Tradisi Male dan Relevansinya dalam Dakwah Islam di Jembrana-Bali. Jurnal Bimas Islam, 12(1).

Salim, Abd. M. (1999). Jalan Lurus Menuju Hati Sejahtera: Tafsir Surat Al Fatihah. Yayasan Kalimah.

Santrock, J. W. (2017). Psikologi Pendidikan. Mc Graw Hill.

Shihab, H. M. Q. (1999). Fatwa-fatwa Seputar Ibadah Mahdah. Mizan.
Solina, W., Sari, A. N., \& Alfaiz, A. (2020). Efektifitas Reinforcement Negatif dalam Meningkatkan Percaya Diri Peserta Didik. Jurnal Neo Konseling, 2(2): Article 2. https://doi.org/10.24036/00265kons202 0

Sujiantari, N. K., Sujana, I. N., \& Zukhri, A. (2016). Pengaruh Reward dan Punishment terhadap Motivasi Belajar Siswa dalam Pembelajaran IPS (Studi Pada SMP Negeri 1 Singaraja Kelas VIII Tahun Ajaran 2015/2016). Jurnal Pendidikan Ekonomi Undiksha, 7(2).

Tim Penyusun Kamus Pusat Bahasa. (2016). Kamus Besar Bahasa Indonesia. Balai Pustaka.

Ulya, K. (2020). Pelaksanaan Metode Pembiasaan di Pendidikan Anak Usia Dini Bina Generasi Tembilahan Kota. ASATIZA: Jurnal Pendidikan, 1(1): 4960.

Umar, U. (2018). Analisis Konstruktif Teori Belajar Behaviorisme dalam Proses Pembelajaran di Sekolah. EL-Muhbib: Jurnal Pemikiran dan Penelitian Pendidikan Dasar, 2(1): 41-52.

Wuryandani, W., Fathurrohman, F., \& Ambarwati, U. (2016). Implementasi Pendidikan Karakter Kemandirian di Muhammadiyah Boarding School. Jurnal Cakrawala Pendidikan, 35(2): Article https://doi.org/10.21831/cp.v15i2.9882

Yasyakur, M. (2017). Strategi Guru Pendidikan Agama Islam dalam Menanamkan Kedisiplinan Beribadah Sholat Lima Waktu. Edukasi Islami: Jurnal Pendidikan Islam, 5(09): 35.

Yusuf, M. (2018). Reward dan Punishment dalam Pembelajaran PAI di Madrasah Aliyah Darussalam Krempyang Tanjunganom Nganjuk. Jurnal Pikir $\square$ : Jurnal Studi Pendidikan dan Hukum 
Islam, $\quad 4(2): \quad$ Article 2. http://ejournal.staida-kre

mpyang.ac.id/index.php/pikir/article/view/1 19

Behaviorisme. Ta'Limuna: Jurnal Pendidikan Islam, 4(1): 1-20.

Zamzami, M. R. (2018). Penerapan Reward https://doi.org/10.32478/ta.v4i1.111

And Punishment dalam Teori Belajar 